\title{
Perfil microbiológico e de resistência antimicrobiana in vitro de bactérias isoladas do útero de éguas subférteis
}

Microbiological and antimicrobial resistance profile in vitro of bacteria isolated from the uterus of subfertile mares

\section{Antonio Brito da Silva Filho', Laís Querino Barbosa Freire ${ }^{2}$, Wisley da Silva Moraes ${ }^{2}$, Illanna de Souza Lima Brandão', Tuane Nunes Batista ${ }^{2}$, Marcelo Mendonça², Elizabete Rodrigues da Silva², Gustavo Ferrer Carneiro ${ }^{1}$}

Universidade Federal Rural de Pernambuco, UFRPE, Rua Dom Manoel de Medeiros, S/N, Dois Irmãos, Recife-PE, Brasil'; ; Universidade Federal do Agreste de Pernambuco, UFAPE, Garanhuns-PE ${ }^{2}$

\section{Resumo}

Objetivou-se avaliar os principais microrganismos isolados do útero de éguas subférteis e o perfil de resistência a agentes antimicrobianos in vitro das bactérias. Foram coletadas amostras de 41 éguas com histórico de subfertilidade. Para cultura bacteriana as amostras foram armazenadas em tubos contendo caldo BHI e para cultura fúngica contendo Solução de $\mathrm{NaCl}$ a $0,9 \%$ e encaminhadas para o LABRAPE-UFRPE. As bactérias isoladas foram submetidas ao teste de sensibilidade in vitro para Amicacina, Gentamicina, Enrofloxacina, Azitromicina, Ceftriaxona, Tetraciclina, Penicilina e Ampicilina. Do total de amostras, 75,6\% apresentaram isolamento microbiológico, sendo $25,8 \%$ Staphylococcus spp.; 12,9\% bacilos Gram-negativos não fermentadores de lactose; $3,22 \%$ Streptococcus $\beta$-hemolítico; 3,22\% E. coli; 3,22\% Klebsiella spp. e 3,22\% Proteus spp.; $22,6 \%$ Bacillus spp. e 6,45\% Micrococcus spp. Dentre as amostras isoladas para fungos $6,45 \%$ foram Cladosporium spp. Observou-se que 12,9\% dos animais apresentaram infecção mista. 95,23\% das bactérias foram sensíveis para Amicacina; 90,47\% para Gentamicina, Enrofloxacina, Tetraciclina e Ceftriaxona e 80,95\% para Azitromicina. Penicilina apresentou 95,24\% das amostras resistentes, com 100\% das bactérias Gram-negativas e 70\% para Ampicilina. A endometrite bacteriana foi a mais prevalente. A presença de infecção fúngica reforça a capacidade desses microrganismos em desenvolver endometrite. Os macrolídeos mostraram-se efetivos e os $\beta$-Lactâmicos inviáveis contra bactérias Gram-negativas.

Palavras chaves: infecção uterina, antibiograma, fungos, equinos.

\section{Abstract}

The objective of this study was to evaluate the main microorganisms isolated from the uterus of subfertile mares and the resistance profile to antimicrobial agents in vitro of the bacteria. Samples were collected from 41 mares with a history of subfertility. For bacterial culture the samples were stored in tubes containing BHI broth and for fungal culture containing $0.9 \% \mathrm{NaCl}$ solution and sent to LABRAPE-UFRPE. The isolated bacteria were subjected to the in vitro sensitivity test for Amikacin, Gentamicin, Enrofloxacin, Azithromycin, Ceftriaxone, Tetracycline, Penicillin and Ampicillin. 75.6\% of the samples presented microbiological isolation, being 25.8\% Staphylococcus spp.; 12.9\% nonlactose-fermenting Gram-negative bacilli; $3.22 \% \quad \beta$-hemolytic streptococcus; $3.22 \%$ E. coli; $3.22 \%$ Klebsiella spp. and 3.22\% Proteus spp.; 22.6\% Bacillus spp. and 6.45\% Micrococcus spp. Among the isolated samples for fungi $6.45 \%$ were Cladosporium spp. It was observed that $12.9 \%$ of the animals had mixed infection. 95.23\% of the bacteria were sensitive to Amikacin; $90.47 \%$ for Gentamicin, Enrofloxacin, Tetracycline and Ceftriaxone and 80.95\% for Azithromycin. Penicillin showed 95.24\% of resistant samples, with 100\% of Gram-negative bacteria and $70 \%$ for Ampicillin. Bacterial endometritis was the most prevalent. The presence of fungal infection reinforces the ability of these microorganisms to develop endometritis. Macrolides were effective and $\beta$-Lactamics were not viable against Gram-negative bacteria.

Keywords: Uterine infection, antibiogram, fungi, horses. 
Silva Filho et al. Perfil microbiológico e de resistência antimicrobiana in vitro de bactérias isoladas do útero de éguas subférteis.

\section{Introdução}

Dentre as enfermidades que acometem o sistema reprodutivo das fêmeas equinas, a endometrite é considerada uma das mais importantes, pois as alterações causadas no endométrio uterino devido ao processo infeccioso e inflamatório levam à incapacidade de concepção, morte embrionária precoce e encurtamento da fase lútea, exercendo impacto econômico significativo (Diel de Amorim et al., 2015), já que os animais afetados apresentam ciclo estral irregular, requerem manejo intensivo e exigem maior número de ciclos estrais para a obtenção de um produto viável, resultando no incremento dos custos de produção (Liu, 2011).

Fêmeas multíparas com idade superior a 14 anos, que demonstrem alteração na conformação vulvar, tenha sido submetida a várias estações de montas por um ou mais períodos consecutivos, útero suspenso, e cérvix que não relaxa no período do estro, podem tornar-se predispostas a endometrite, assim como patologias como pneumovagina, desequilíbrio endócrino, monta natural, aborto, partos distócitos, retenção da placenta ou falhas sanitárias no manejo, podem também ser considerados como fatores predisponentes (Diel de Amorim et al., 2015).

As doenças uterinas podem apresentar diversas classificações, de acordo com sua causa, tais como: endometrite persistente pós-cobertura; endometrite crônica; endometrite subclínica; piometra; metrite aguda pós-parto; e endometrite venérea (Katila, 2016). Na maioria das vezes, a endometrite infecciosa apresenta origem bacteriana, sendo as bactérias Streptococcus spp., Escherichia coli, Pseudomonas aeruginosa e Klebsiella pneumonie, mais identificadas nas culturas microbiológicas (Riddle et al., 2007; Troedsson, 2011). Outras bactérias aeróbias isoladas do útero de éguas incluem Corynebacterium spp., Staphylococcus spp., Enterobacter spp., Actinobacter spp., Proteus spp., e Citrobacter spp. (Troedsson, 2011). Todavia, fungos leveduriformes e filamentosos, são potencialmente patogênicos para o endométrio das éguas (Ghasemzadehnava et al, 2004; LeBlanc, 2008). Sendo Candida spp. e Aspergillus spp. os microrganismos mais comumente isolados (Coutinho da Silva; Alvarenga, 2011)

Há uma constante variação nas espécies de bactérias isoladas, assim como na susceptibilidade aos antibióticos que podem variar de uma população para outra e entre diferentes regiões. Uma antibioticoterapia inadequada pode resultar em falhas no tratamento e consequentemente perdas econômicas (Pyorala et. al., 2014). Pode levar ainda a uma resistência antimicrobiana, fator de preocupação mundial. Embora não se conheça exatamente o mecanismo, o uso repetitivo, prolongado e excessivo de antimicrobianos aparentemente está associado ao aumento da incidência de endometrites fúngicas (Liu, 2011). O refluxo de antibióticos e desinfetantes usados repetidas vezes em tratamentos uterinos podem levar a uma alteração da microbiota vaginal criando um ambiente propício para o desenvolvimento de agentes patogênicos (Coutinho da Silva; Alvarenga, 2011).

Um dos fatores mais importantes para permitir a sobrevivência dos microrganismos em condições adversas é a resistência antimicrobiana, através desta foram selecionadas características pelas quais as bactérias tornaram-se capazes de escapar da ação dos fármacos. Com o passar das décadas, essa resistência sofreu um aumento considerável, estabelecendo-se como umas das principais preocupações em saúde pública (Kuen, 1994).

Na medicina veterinária, o uso intensivo de antimicrobianos pode resultar na seleção de bactérias resistentes, tornando a ação dos princípios ativos menos eficazes (Vaz, 2009) e permitindo que bactérias patogênicas se adaptem ao ambiente competitivo. A associação de fatores de virulência e resistência a antibióticos são importantes mecanismos necessários para sobrevivência das bactérias sob condições adversas (Beceiro, et al., 2013). Desta forma, o objetivo desse trabalho foi traçar um perfil de sensibilidade e resistência aos antimicrobianos a partir de isolados bacterianos de útero de éguas subférteis.

\section{Material e Métodos}

Foram coletadas amostras de 41 éguas de várias raças compreendendo uma faixa etária entre 421 anos, com histórico de subfertilidade baseada em coletas de embrião ou prenhez negativa por três vezes consecutivas, em diferentes fases do ciclo estral, provenientes de propriedades localizadas na região Agreste do estado de Pernambuco, durante a estação de monta de 2019. As coletas foram realizadas com o uso de coletores comerciais do tipo escova citológica (CCE). O uso de animais neste experimento foi previamente autorizado pelo Comitê de Ética no Uso de Animais (CEUA) de acordo com o protocolo 
Silva Filho et al. Perfil microbiológico e de resistência antimicrobiana in vitro de bactérias isoladas do útero de éguas subférteis.

\subsection{2/2019-76.}

Após o esvaziamento do reto com auxílio de luva de palpação transretal, as regiões perianal e perivaginal foram devidamente higienizadas com Clorexidina $2 \%$. Posteriormente, o coletor comercial tipo escova citológica duplamente guardada (PROVAR $\left.{ }^{\circledR}\right)$ foi introduzido protegido com a mão. A escova citológica foi inserida através da cérvix com auxílio do dedo, seguido de rompimento da primeira proteção plástica, e exposição do conjunto coletor, já introduzido no útero de forma transcervical. Com o conjunto coletor dentro do útero, o lacre externo foi rompido, permitindo o contato da escova citológica com a parede do endométrio, sendo realizados suaves movimentos rotatórios. Depois de colhida a amostra, puxou-se a haste interna de volta para dentro do tubo externo e após retirar todo o conjunto de dentro do útero às amostras foram encaminhadas para uma bancada estéril. Com o auxílio de uma chama proveniente de um Bico de Bunsen, foi realizado um esfregaço em lâmina estéril para citologia e posteriormente um swab estéril foi esfregado na escova citológica para obtenção de uma alíquota da amostra para cultivo bacteriano e outra alíquota para cultivo fúngico. As amostras para cultura bacteriana foram armazenadas em tubos de ensaio de vidro com tampa rosqueável, estéreis contendo meio BHI Caldo (Brain Heart Infusion). As amostras para cultivo fúngico foram armazenadas em tubos de ensaio de vidro com tampa rosqueável estéreis, contendo Solução de $\mathrm{NaCl}$ a $0,9 \%$. Ambas as amostras de cada égua foram devidamente identificadas e acondicionadas dentro de uma caixa de transporte de isopor sob refrigeração e encaminhadas para o Laboratório de Reprodução Animal de Pernambuco (LABRAPE) da UFRPE-UAG para as análises de cultivo e identificação bacteriana e fúngica, assim como realização dos testes de sensibilidade antimicrobiana.

No laboratório, as amostras em caldo BHI foram incubadas em estufa sobre aerobiose a $\pm 37^{\circ} \mathrm{C}$ por 24 horas. Já as amostras em Solução de $\mathrm{NaCl}$ a $0,9 \%$ foram semeadas em placas contendo Ágar Saubourod Dextrose $4 \%$ e posteriormente incubados em estufa em aerobiose a $\pm 29^{\circ} \mathrm{C}$, por 7 dias. $\mathrm{O}$ crescimento fúngico foi avaliado a cada 24 horas. Após as 24 horas de incubação das amostras para cultura bacteriana, as mesmas foram semeadas em placas contendo Agar Sangue de Carneiro 6\% (v/v) e Agar Maconkey e posteriormente incubadas novamente em estufa sobre aerobiose na temperatura de $\pm 37^{\circ} \mathrm{C}$ por até 48 horas. Após o período de incubação foram avaliadas as características de crescimento das colônias nas placas, como produção de hemólise, pigmento e características morfotintoriais e foram confeccionadas lâminas pelo método de coloração Gram de acordo com Quinn et al. (1994), para diferenciação entre cocos e bacilos Gram positivos ou Gram negativos, sendo ambos posteriormente submetidos à prova da Catalase.

Para identificação das enterobactérias foram utilizadas as seguintes provas bioquímicas: produção de urease, Caldo Nitrato, teste de VM/VP (VM - reação de Vermelho de Metila; VP - reação de Voges- Proskauer), teste em Ágar SIM (S - produção de H2S; I - produção de Indol; M - motilidade) e teste em Ágar Citrato (utilização do carbono do citrato) e então identificadas de acordo com a metodologia empregada por Carter (1988) e Quinn et al. (1994). Para identificação dos cocos Grampositivos catalase positivas, foram utilizados os seguintes testes: Teste da Bacitracina e Novobiocina, Coagulase e CAMP-teste, de acordo com a ANVISA (2004). Para identificação morfológica dos fungos, foram observados os aspectos macro e micromorfológicos das estruturas somáticas e reprodutivas, comparando os resultados com base na literatura específica (Ellis, 1971; Ellis, 1976; Sutton, 1980; Domsh et al., 2007).

Os testes de sensibilidade/resistência antimicrobiana in vitro das bactérias isoladas foram realizados utilizando a técnica de difusão em disco em Müeller Hinton, segundo o CLSI (2008), sendo testadas as seguintes drogas: Amicacina, Gentamicina, Enrofloxacina, Azitromicina, Ceftriaxona, Tetraciclina, Penicilina e Ampicilina para as bactérias Gram-negativas. Os isolados foram reativados em caldo $\mathrm{BHI}$, incubados a $37^{\circ} \mathrm{C}$, durante $16-18 \mathrm{~h}$. As culturas foram diluídas em caldo BHI para $10^{5} \mathrm{UFC}$. $\mathrm{mL}^{-1}$, de acordo com a escala de MacFarland, plaqueadas em ágar Müeller Hinton e incubadas as enterobactérias a $37^{\circ} \mathrm{C}$ e os Staphylococcus spp. a $35^{\circ} \mathrm{C}$, durante $24 \mathrm{~h}$. Os diâmetros dos halos de inibição foram medidos e o resultado comparado com o padrão do CLSI.

Os resultados obtidos foram analisados por meio de modelo linear generalizado, considerando-se as distribuições binomial (para testar o efeito dos diagnósticos citológico e microbiológico) ou multinomial (para testar o efeito dos diferentes antibióticos), com link das funções igual a logit e logit cumulativo, respectivamente (UNESP, 2011). Diferenças entre métodos de diagnostico foram consideradas significativas de acordo com o teste Qui-quadrado $(\mathrm{P} \leq 0,05)$. Diferenças entre antibióticos e níveis de sensibilidade ao antibiótico foram comparadas pelo teste Tukey $(\mathrm{P} \leq 0,05)$. Todas as análises foram realizadas com auxílio do software estatístico RStudio (Core Team, 2018). 
Silva Filho et al. Perfil microbiológico e de resistência antimicrobiana in vitro de bactérias isoladas do útero de éguas subférteis.

\section{Resultados}

No presente trabalho foi observado que 65,8\% (27/41) das éguas foram positivas na ciotologia e $75,6 \%$ (31/41) apresentaram isolamento microbiológico positivo (Figura 1), porém não houve diferença estatística entre ambos os testes diagnósticos. A frequência de microrganismos isolados é apresentada na Tabela 1. Dentre os isolamentos microbiológicos positivos, $25,8 \%$ das amostras foram identificadas como Staphylococcus spp.; 12,9\% para bacilos Gram-negativos não fermentadores de lactose; 3,22\% para Streptococcus $\beta$-hemolítico; 3,22\% para E. coli; 3,22\% para Klebsiella spp. e 3,22\% para Proteus spp. além disso, 22,6\%-das amostras apresentaram crescimento de bactérias do gênero Bacillus spp. e 6,45\% Micrococcus spp. Dentre as amostras isoladas para fungos 6,45\% foram positivas para Cladosporium spp. Também foi observado que em $12,9 \%$ das amostras houve a presença de infecção mista, quando há o envolvimento de mais de um microrganismo, sendo uma amostra positiva para Klebsiella spp. e E. colli, uma para Staphilococcus spp. e Penicilium spp., uma para Staphylococcus spp. e Cladosporium spp. e uma para Klebsiella spp. e Trichosporum spp.

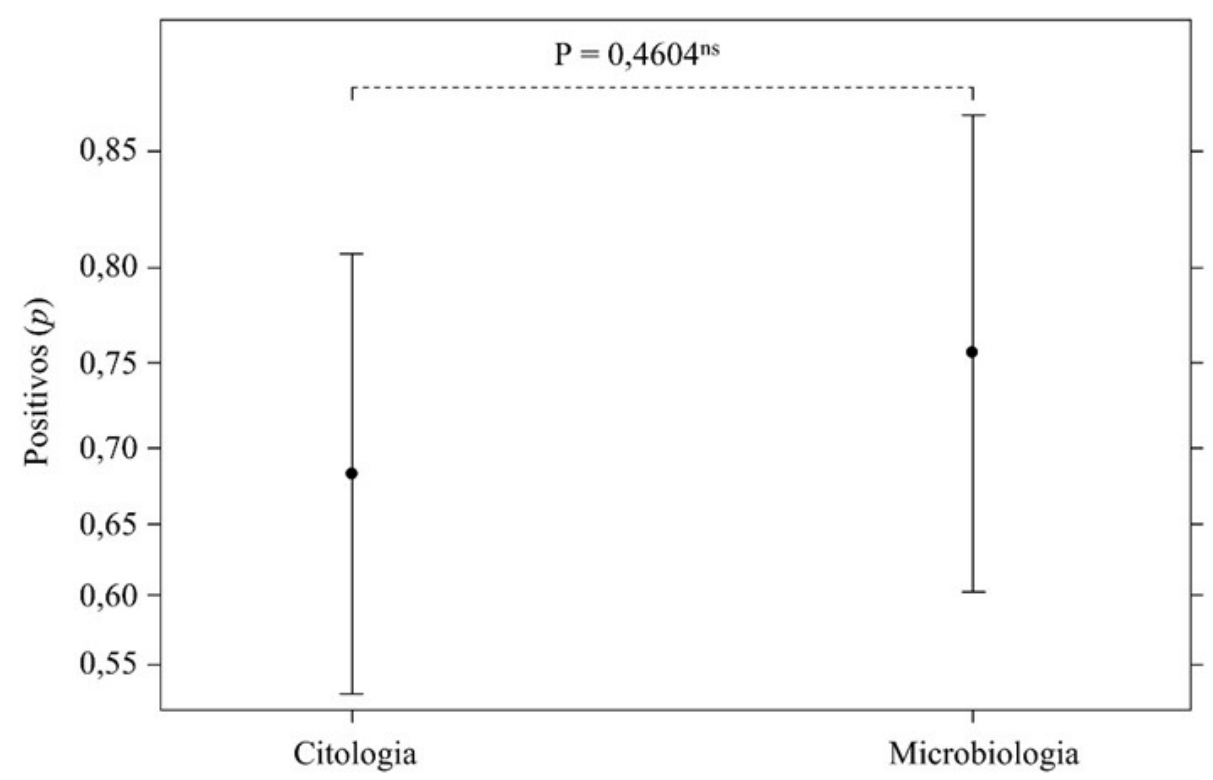

Figura 1. Probabilidade $(p)$ de diagnóstico positivo para endometrite entre os métodos de Citologia e Microbiologia.

Tabela 1. Frequências absoluta e relativa de microrganismos isolados por cultura microbiológica do útero de éguas da região do Agreste Pernambucano na estação de monta de 2019.

\begin{tabular}{|c|c|c|}
\hline Microrganismos isolados & Frequência Absoluta & Frequênica Relativa \\
\hline Stapylococcus spp. & 8 & $25,80 \%$ \\
\hline Bacilos Gram-negativos NFL & 4 & $12,90 \%$ \\
\hline Streptococcus $\beta$-hemolitico & 1 & $3,22 \%$ \\
\hline Escherichia coli & 1 & $3,22 \%$ \\
\hline Klebsiella spp. & 1 & $3,22 \%$ \\
\hline Proteus spp. & 1 & $3,22 \%$ \\
\hline Cladosporium spp. & 2 & $6,45 \%$ \\
\hline Klebsiella spp. e Escherichia coli & 1 & $3,22 \%$ \\
\hline Staphilococcus spp. e Penicilium spp & 1 & $3,22 \%$ \\
\hline Staphylococcus spp. e Cladosporium spp. & 1 & $3,22 \%$ \\
\hline Klebsiella spp. e Trichosporon spp. & 1 & $3,22 \%$ \\
\hline Bacillus spp. & 7 & $22,60 \%$ \\
\hline Micrococcus spp. & 2 & $6,49 \%$ \\
\hline Total & 31 & $100 \%$ \\
\hline
\end{tabular}

*NFL - Não Fermentadores de Lactose 
Silva Filho et al. Perfil microbiológico e de resistência antimicrobiana in vitro de bactérias isoladas do útero de éguas subférteis.

Em relação ao perfil de sensibilidade aos antibióticos testados foi observado que 95,23\% das amostras apresentaram sensibilidade para Amicacina; 90,47\% para Gentamicina, Enrofloxacina, Tetraciclina e Ceftriaxona e 80,95\% para Azitromicina. Em relação ao perfil de resistência (Figura 2) a Penicilina apresentou 95,24\% das amostras resistentes, com 100\% das bactérias Gram-negativas resistentes, diferindo-se estatisticamente dos demais antibióticos testados e $70 \%$ dessas amostras foram resistentes para Ampicilina, porém não foi observada diferença estatística entre os demais antibióticos testados.

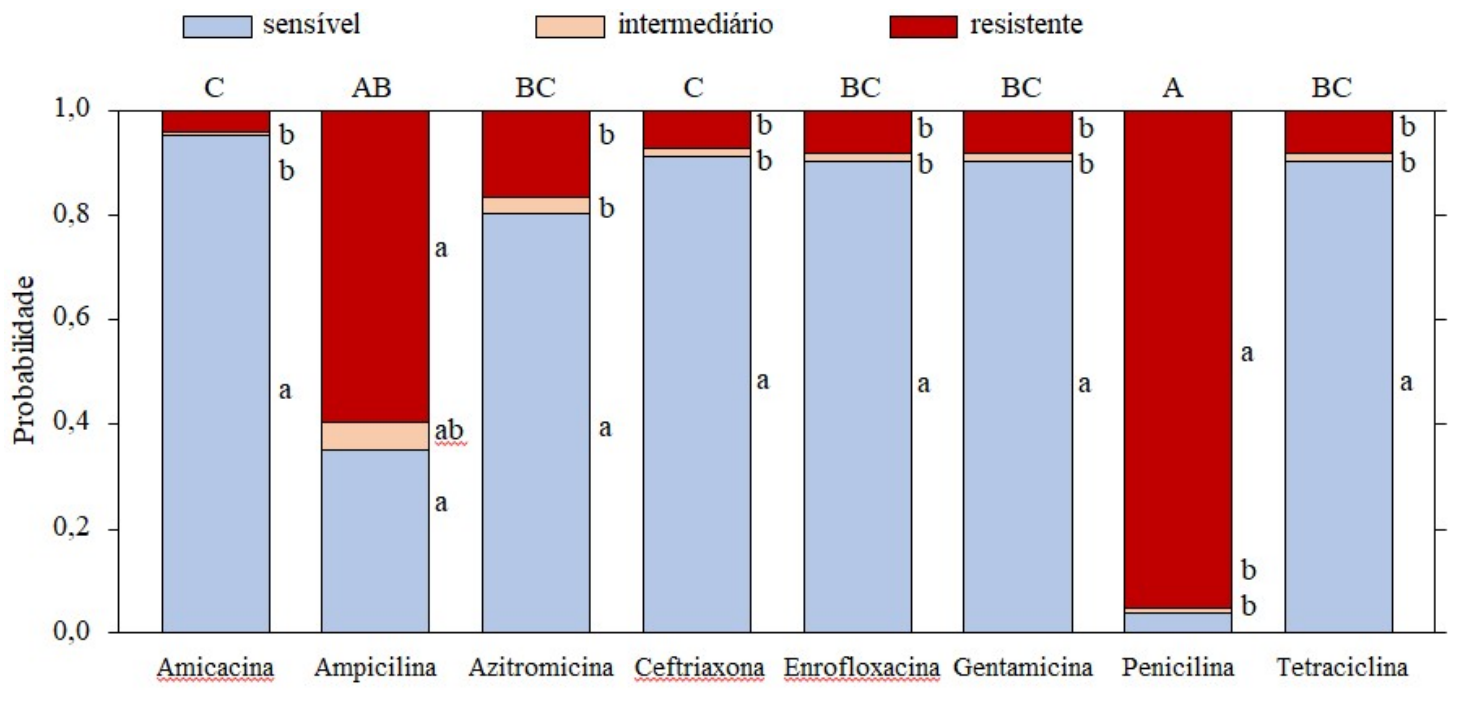

Antibióticos

Figura 2. Perfil de resistência e sensibilidade a antibióticos de bactérias isoladas do útero de éguas subférteis localizadas no Agreste de Pernambuco, onde as letras maiúsculas correspondem às comparações estatísticas entre os antibióticos testados e as letras minúsculas correspondem à capacidade de resistência e sensibilidade das bactérias aos determinados antibióticos.

\section{Discussão}

Das 41 éguas coletadas, 27 foram positivas no exame citológico $(65,8 \%)$, resultado um pouco inferior às culturas microbiológicas positivas nesse experimento (75,6\%), Riddle et al. (2007) ao avaliarem a citologia uterina observaram que éguas com menos de 2 PMNs por campo (x400 objetiva) apresentavam maiores taxas de prenhez (60\% por ciclo) comparado com éguas com 2 a 5 PMNs por campos (x400), que apresentavam taxa de prenhez de 23\%. Em nosso estudo, consideramos citologia positiva a presença de pelo menos 1 PMN por campo. Os mesmos autores relataram que infecções associadas com E. coli, eram menos prováveis de serem associadas com citologia positiva. Em nosso estudo obtivemos 1 caso de égua infectada por E. coli (Tabela 1) que também apresentou citologia positiva. Das 41 amostras, $75.6 \%$ apresentaram culturas microbiológicas positivas, valor um pouco superior ao encontrado por Oliveira et al. (2010) que obtiveram $64 \%$ das amostras positivas em um estudo realizado com éguas subférteis com suspeitas de endometrite da mesma região deste estudo semelhantes aos encontrados por Cabrera et al. (2016) que encontraram isolamento microbiológico em $71,4 \%$ das 196 éguas coletadas com endometrite.

Em relação à frequência de bactérias isoladas, o presente estudo apresentou maior frequência de isolamento para as bactérias do gênero Staphylococcus spp. seguidos por bacilos Gram-negativos não fermentadores de lactose, Streptococcus $\beta$-hemolítico, E. coli, Klebsiella spp. e Proteus spp. Resultados que vão de acordo com os encontrados por Cabrera et al. (2016) que observaram maior frequência $(47,1 \%)$ de isolados para bactérias do gênero Staphylococccus. Em contrapartida, esses resultados diferem dos encontrados por Câmara et al. (2013) em que E. coli foi a bactéria com maior prevalência, correspondendo a 53,33\%. No entanto, esse percentual de isolamento de E. coli, foi observado em amostras de animais clinicamente sadios e que não apresentaram citologia positiva, o que de acordo com Leblanck e Causey (2009), pode representar contaminação das amostras, pois amostras de éguas com culturas positivas, associadas a citologia negativa e ausência de sinais clínicos, deve-se considerar a 
Silva Filho et al. Perfil microbiológico e de resistência antimicrobiana in vitro de bactérias isoladas do útero de éguas subférteis.

possibilidade de contaminação.

Já Benko et al. (2015), em um estudo realizando coletas em éguas Puro Sangue Inglês durante o cio do potro, observaram que os Streptococcus $\beta$-hemolíticos, foram mais prevalentes, correspondendo a $40,4 \%$ das amostras e as bactérias do gênero Staphylococcus spp. corresponderam a 17,7\% das 307 amostras consideradas positivas. No entanto, os autores não descreveram se as éguas em que foram coletadas as amostras apresentavam algum histórico de subfertilidade ou sintomatologia de endometrite, tendo em vista, que a pesquisa foi feita em cima de avaliações ginecológicas de rotina em uma central de garanhões PSI.

No presente estudo também foi observado o isolamento de 22,6\% (7/31) das amostras para bactéria do gênero Bacillus spp. e 6,45\% (2/31) para Micrococcus spp. De acordo com Riddle et al. (2007), Bacillus spp. e Micrococcus spp. são microrganismos comensais da pele e mucosa do trato urogenital, o que pode levar a diagnósticos falsos positivos devido a contaminação das amostras (Buczkowska et al., 2014; Cadario, 2014). Porém, deve-se levar em consideração que em determinados casos as bactérias podem se fixar na forma de biofilme nas dobras endometriais do útero levando ao desenvolvimento de endometrites subclínicas crônicas (Ferris, 2017).

Observou-se ainda que 12,9\% (4/31) das culturas apresentaram contaminação mista, ou seja, quando mais de um microrganismo estão envolvidos, dentre elas $1 / 31$ foi positivo para Klebsiella spp. e E. coli; 1/31 para Staphylococcus spp. e Penicilium spp.; 1/31 para Staphylococcus spp. e Cladosporium spp. e 1/31 para os gêneros Klebsiella e Trichosporon. Oliveira et al. (2007) e Oliveira et al. (2010) também encontraram infecções mistas em 16,6\% e 10,9\% dos isolados microbiológicos respectivamente, sendo estas ocorridas por bactérias. Ainda de acordo com os mesmos autores as infecções mistas podem agravar as lesões no endométrio, além de dificultar o tratamento devido à variação de sensibilidade ao antimicrobiano utilizado que pode ocorrer. Poucos estudos descrevem as infecções mistas entre fungos e bactérias em útero de éguas, porém de acordo com Frontoso et al. (2008) como as bactérias que ocasionam endometrites são essencialmente contaminantes e oportunistas, infecções mistas entre fungos e bactérias também podem ocorrer. Ribas et al. (2014) em estudo realizado com 84 éguas, observaram a prevalência de $2,35 \%$ de infecções mistas entre fungos e bactérias, sendo a Candida spp. o agente fúngico isolado.

Além disso, 6,45\% (2/31) foram positivas exclusivamente para contaminação fúngica, sendo o Cladosporium spp. o gênero isolado. Estudos realizados por Amaral et al. (2007), mostram que os fungos filamentosos do gênero Cladosporium spp. apresentaram frequência de 5,1\% e uma alta correlação com processos inflamatórios crônicos do útero de éguas, chegando a uma prevalência de $75 \%$ dos isolados para esse fungo relacionados a processos inflamatórios, perdendo apenas para os fungos do gênero Aspergillus spp. Batista et al., (2008) demonstram a prevalência de $60 \%$ de casos de endometrite fúngica, causada por Candida sp. em culturas microbiológicas de éguas oriundas da Zona da Mata de Pernambuco. Assim como, Ribas et al. (2014) demonstraram resultados com prevalência de $20,8 \%$ de endometrite fúngica, sendo Candida sp. o fungo mais prevalente, houve também incidência de fungos filamentosos como o Trichosporon penicillatum.

$\mathrm{O}$ que difere deste trabalho, onde o agente com maior prevalência de isolamento foi $o$ Cladosporium spp. o que pode ser justificado pelo fato de que este agente, além de ser um dos mais prevalentes na microbiota vaginal de éguas sadias (Azarvandi et al., 2017), o que pode justificar o seu desenvolvimento como microrganismo oportunista, também é considerado um dos fungos mais facilmente isolados do ambiente, além de fazer parte da microbiota natural da pele de humanos, e que dependendo da espécie associada, pode apresentar um alto grau de patogenicidade em tecidos devido a sua capacidade de digerir proteínas (Menezes et al., 2017), o que pode levar a uma endometrite iatrogênica, devido à alta capacidade de contaminação de materiais e instrumentos por parte dos esporos desse fungo, como também, a falta de cuidados e higiene por parte dos veterinários.

Em relação ao perfil de sensibilidade aos antimicrobianos (Figura 2) 95,23\% das amostras apresentaram sensibilidade para Amicacina; 90,47\% para Gentamicina, Enrofloxacina, Tetraciclina e Ceftriaxona e 80,95\% para Azitromicina. Cabrera et al. (2016) encontraram índices de maior sensibilidade para Enrofloxacina (93\%), no entanto, também observaram resultados expressivos de sensibilidade para Amicacina (73\%). Já Bandeira et al. (2017) apresentaram índices de sensibilidade para Amicacina de 89\%, seguido de Enrofloxacina 76\%, Gentamicina 72,7\%, Ceftriaxona 71\%.

Em relação ao perfil de resistência aos antimicrobianos (Figura 2) a Penicilina apresentou 95,24\% das amostras resistentes, com 100\% das bactérias Gram-negativas resistentes, das quais 70\% foram resistentes para Ampicilina. Resultados esses semelhantes aos encontrados por Oliveira et al. 
Silva Filho et al. Perfil microbiológico e de resistência antimicrobiana in vitro de bactérias isoladas do útero de éguas subférteis.

(2007) que também encontraram 100\% de resistência a Penicilina das amostras testadas. Bandeira et al. (2017) demonstram que resistência para Ampicilina de 77\%, o que vai de acordo com os resultados encontrados neste estudo, no entanto, para Penicilina, o perfil de resistência foi de 64\%. Entretanto, Cabrera et al. (2016) apontaram em seus estudos um baixo índice de sensibilidade para a Penicilina e Ampicilina de 2,9\% e 10\% respectivamente, levando a compreender que $97,1 \%$ das amostras foram resistentes ou intermediárias para a Penicilina e $90 \%$ para Ampicilina.

$\mathrm{O}$ alto índice de resistência aos $\beta$-Lactâmicos como Penicilina e Ampicilina pode ocorrer devido ao uso indiscriminado de antimicrobianos no combate a diferentes enfermidades o que leva à seleção de cepas resistentes prejudicando a eficácia do tratamento com essas drogas (Haveri et al., 2005). Existem poucos dados estatísticos na literatura a respeito da quantidade de fármacos utilizados pela medicina veterinária, no entanto, estima-se que 70\% desses medicamentos sejam antibióticos (Thiele-Bruhn, 2003; Díaz-Cruz e Barceló, 2007). Estatísticas europeias apontam o uso de aproximadamente 4,6 milhões de kg de antibióticos destinados a produção animal, sendo as Tetraciclinas, os $\beta$-Lactâmicos e as Cefalosporinas os produtos mais utilizados

Já na reprodução animal, principalmente em casos de endometrite é comum o uso de diversos antibióticos, tais como Ceftiofur, Gentamicina, Ticarcilina com Ácido Clavulânico, Ampicilina, Penicilinas, Amicacina e Tetraciclinas (Dascanio, 2011) através de infusões intrauterinas (LeBlanc e Causey, 2009). No entanto, a grande maioria desses fármacos com exceção da Amicacina, não apresentam indicação para uso tópico intrauterino (Viana, 2014). Fato importante, pois atualmente sabese que a principal fonte de resistência antimicrobiana, não está ligada a capacidade residual do fármaco, mas sim ao uso indiscriminado de antibióticos no que diz respeito a doses e vias de administrações (Sales, 2015).

A resistência antimicrobiana ocorre quando os microrganismos adquirem genes de resistência aos antibióticos através de mutação gênica ou como consequência da aquisição destes genes de outros microrganismos já resistentes. Neste último caso, os genes de resistência podem estar presentes em plasmídeos que contem outros genes que permitem sua seleção em ambientes nos quais haja a presença seletiva de antimicrobianos (Rodriguez e Menéndez, 2005).

Nos casos de microrganismos resistentes a drogas que fazem parte do grupo dos $\beta$-Lactâmicos, como é o caso dos dados encontrados neste estudo, os mesmos possuem genes conhecidos como genes "bla" podendo ser encontrados tanto em plasmídeos, como no cromossomo das bactérias, os mesmos são responsáveis por codificarem a síntese da enzima $\beta$-lactamase. Essa enzima pode ser encontrada no espaço periplasmático e impede que o antibiótico entre na célula através da hidrólise do anel $\beta$ Lactâmico, estrutura presente nas drogas que fazem parte desse grupo, os quais são responsáveis por ligarem-se as Proteínas Ligadoras de Penicilinas (PBPs) que são enzimas bacterianas atuantes no processo de transpeptidação durante a biossíntese da parede celular (Olsen et al., 2006; Andrade, et al., 2017).

\section{Conclusões}

Pode-se concluir que a endometrite bacteriana foi a mais prevalente neste estudo, os Macrolídeos se mostraram efetivos contra os agentes testados e os $\beta$-Lactâmicos inviáveis principalmente para endometrites causadas por bactérias Gram-negativas. No entanto, a presença de infecção fúngica reforça a capacidade desses microrganismos em desenvolver endometrite. Os resultados encontrados reforçam a importância da identificação do agente causador através de cultura microbiológica associado a antibiograma para se tomar a decisão mais eficiente em relação ao tratamento, diminuindo assim a possibilidade de resistência aos antimicrobianos.

\section{Referências}

Amaral MG, Pimentel MM, Fiala SM, Schramm EG, Xavier e Mendonça M. Endometrite equina: fungos e bactérias. Arch Zootec. n.56, v.216, p.875-884, 2007.

Andrade LN, Darini ALC. Bacilos gram-negativos produtores de beta-lactamases: que bla bla bla é esse?. J Infect Control, Brazil, n.1, v.6, p.16-25, 2017.

ANVISA. Detecção e Identificação de Bactérias de Importância Médica. Disponível em: < http://www.anvisa.gov.br/servicosaude/microbiologia/mod 5 2004.pdf $>$ Acesso em: 12 de junho de 2019. 
Silva Filho et al. Perfil microbiológico e de resistência antimicrobiana in vitro de bactérias isoladas do útero de éguas subférteis.

Azarvandi A, Talebkhan GM, Khosravi A, Hosseini A, Gharagozloo F. Isolation and identification of molds flora in external genital tract of healthy mares. J of Vet Research, n.1, v.72, p.103-110, 2017.

Bandeira RS, Thomasini J, Lorenzet G, Martins GV, Novello G, França, RT Lisboa, F. Avaliação microbiológica e teste de sensibilidade in vitro de bactérias isoladas do útero de éguas da raça Crioula. Rev Acad Ciênc Anim, v.15, n.1, p.127-128, 2017.

Batista IO, Oliveira AAF, Pinheiro Júnior JW, Peixoto RM, Teles JAA, Mota RA. Endometrite por Candida sp. e outros microrganismos associados em éguas doadoras de embrião na Zona da Mata do Estado de Pernambuco - Brasil. Med Vet, v.2, n. 4, p.41-44, 2008.

Beceiro A, Tomás M, Bou G. Antimicrobial resistance and virulence: a successful or deleterius association in the bacterial world? Clin Microbiol Rev. v.26, p.185-230, 2013.

Benko TM, Boldizar FN, Hura V, Karamanova M, Petrovic V. Incidence of bacterial pathogens in equine uterine swabs, their antibiotic resistance patterns, and selected reproductive indices in English thoroughbred mares during the foal heat cycle. Med Vet, v.60, n.11, p. 613-620, 2015.

Buczkowska J, Kozdrowski R, Nowak M, Raś A, Staroniewicz Z, Siemieniuch MJ. Comparison of the biopsy and cytobrush techniques for diagnosis of subclinical endometritis in mares. Reprod Biol and Endocrinol v.12, p.27, 2014

Cabrera T, Patorelo M, Alvarenga MA. Prevalência e perfil de sensibilidade bacteriana em éguas com endometrite. Enci Biosf, v.13, n.23, p.1013, 2016.

Cadario, M. Revisiting the diagnosis and the treatment options for an old problem: chronic and postbreeding endometritis in the mare. The Practitioner, v.1, p.21-25, 2014.

Câmara WM, Cancimansi JAN, Shimoda E, Fagundes B, Barreto MAP, SILVA JFS. Identificação e perfil de sensibilidade antimicrobiana de bactérias isolada de éguas suspeitas ou não de endometrite. Rev Bras Ciênc Agrár, v.8, n.4, p.669-674, 2013.

Carter GR. Fundamentos da bacteriologia e micologia veterinária. São Paulo: Roca, p.249, 1988.

CLSI - Clinical and Laboratory Standards Institute, M31-A3, v.28, n.8, 2008.

Core Team, RR. A language and environment for statistical computing. R Foundation for Statistical Computing, Vienna, Austria, 2018

Coutinho da Silva MA, Alvarenga MA. Fungal endometritis. In: McKinnon Angus O, Squires Edward L, Vaala Wendy E, Varner Dickson D (Eds). Equine Reproduction 2nd (ed), Blackwell Publishing Ltd, p.2643-2651, 2011.

Dascanio J. How and when to treat endometritis with systemic or local antibiotics. AAEP Proceedings, v.57, p.24-31, 2011.

Díaz-cruz MS, Barceló D. Recent advances in LC-MS residue analysis of veterinary medicines in the terrestrial environment. Trac-Trends Anal Chem. v.26, p. 637-646, 2007.

Diel de Amorim M, Gartley CJ, Foster RA, Hill A, Scholtz EL, Hayes A, Chenier TS. Comparison of clinical signs, endometrial culture, endometrial cytology, uterine low volume lavage, and uterine biopsy, and combinations in the diagnosis of Equine Endometritis. J Equi Vet Sci, v.44, p.54-61, 2015.

Domsch KH, Gams W, Anderson TH. Compendium of soil fungi. Eching: IHW189, Verlag, p.672, 2007.

Ellis MB. Dematiaceous Hyphomycetes. Kew: Commonwealth Mycological Institute. 1971.

Ellis MB. Dematiaceous Hyphomycetes. Kew: Commonwealth Mycological Institute. 1976.

Ferris, RA. Current understanding of bacterial biofilms and latent infections: A clinical perspective. Rev Bras Reprod Anim, v.41, n.1, p.74-80, 2017.

Frontoso R, De Carlo E, Pasolini MP, Van Der Meulen K, Pagnini U, Iovane G, De Martino L. Retrospective study of bacterial isolates and their antimicrobial susceptibilities in equine uteri during fertility problems. Res Vet Sci, v.84, p.1-6, 2008.

Ghasemzadeh-nava H, Ghasemi F, Tajik P, Shirazi A. A review of mare endometritis in Iran. J Equine Vet Sci, v.24, n.5, p.188-192, 2004.

Haveri M, Suominen S, Rantala L, Honkanen-Buzalski T, Pyörälä S. Comparison of phenotypic and genotypic detection of penicillin G resistance of Staphylococcus aureus isolated from bovine intramammary infection. Vet Microbiol, v.106, p.97-102, 2005.

Katila T. Evaluation of diagnostic methods in equine endometritis. Reprod Biol, v.198, p.8, 2016.

Kuen MJ. Genetic, biochemical and structural studies of biogenesis of adhesive pill in bactéria. Meth and Enzyme. v.236, p.282-306, 1994.

Leblanc MM. When to refer an infertile mare to a theriogenologist. Theriogenology, v.70, p.421-429, 2008 . 
Silva Filho et al. Perfil microbiológico e de resistência antimicrobiana in vitro de bactérias isoladas do útero de éguas subférteis.

Leblanc MM, Causey RC. Clinical and subclinical endometritis in the mare: both threats to fertility. Reprod Domest Anim, v.44, p.10-22, 2009.

Liu, IKM. The diagnosis, causes and treatment of persistent endometritis in the mare. Rev Bras Reprod Anim, v.35, n.2, p.256-261, 2011.

Menezes CP, Pérez ALAL, Lima EO. Cladosporium spp: Morfologia, infecções e espécies patogênicas. Acta Bras, n.1, p.23-27, 2017.

Oliveira IB, Peixoto RM, Silva DR, Pinheiro Junior JW, Oliveira AAF, Mota RA. Etiologia e perfil de sensibilidade de bactérias aeróbias isoladas de éguas suspeitas de endometrite procedentes do Estado de Pernambuco. Med Vet, v.1, n.1, p.19-25, 2007.

Oliveira IB, Peixoto RM, Silva DR, Pinheiro Júnior JW, Oliveira AAF, Mota RA. Análise comparativa entre o exame citológico e microbiológico no diagnóstico de endometrite equina. Vet Zootec, v.17, n.1, p.43-46, 2010.

Olsen JE, Christensen H, Aarestrup FM. Diversity and evolution of blaZ from Staphylococcus aureus and coagulase negative staphylococci. J Antimicrob Chemother, v.57, p.450-460, 2006.

Pyorala S, Taponen J, Katila T. Use of antimicrobials in the treatment of reproductive diseases in cattle and horses. Reprod Dom Anim, v.49, n.3, p.16-26, 2014.

Quinn PJ et al. Clinical Veterinary Microbiology, London: Wolfe, p.648, 1994.

Ribas JA, Carvalho EQ, Stussi JP. Endometrite fúngica em éguas: diagnóstico e implicações clínicopatológicas. Rev Bras Cien Vet, v.21, n.3, p.204-212, 2014.

Riddle WT, Leblanc MM, Stromberg AJ. Relationships between uterine culture, cytology and pregnancy rates in a Thoroughbred pratice. Theriogenology, v.68, n.3, p.395-402, 2007.

Rodríguez JFL, Menéndez JLM. Resistencia a los antimicrobianos y virulência bacteriana. Enferm. Infecc Microbiol Clin, v.23, n.2, p.86-93, 2005.

Sales RL, Rocha JLM, Bressan J. Utilização de hormônios e antibióticos em produtos de origem animal: aspectos gerais e toxicológicos. Nutrire, n.40, v.3, p.409-420, 2015.

Sutton BC. The Coelomycetes: fungi imperfecti with pycnidia, acervuli and stromata. Commonwealth Mycological Institute, p.96, 1980.

Thiele-Bruhn S. Pharmaceutical antibiotic compounds in soils - a review. J. Plant Nutr Soil Sci, v.166, p.145-167, 2003.

Troedsson MHT. Endometritis. In: MCKINNON AO, SQUIRES EL, VAALA WE, VARNER DV, editors. Equine Reproduction, Second Edition. U.K: Wiley- Blackwell; 2011.

UNESP - Universidade Estadual Paulista. Estatística aplicada à ecologia usando o R. Programa de PósGraduação Biologia Animal. São José do Rio Preto, SP Abril, 2011. Diponível em: <https://cran.rproject.org/doc/contrib/Provete-Estatistica_aplicada.pdf>. Acesso em: 24 de fevereiro de 2021.

Vaz EK. Resistência antimicrobiana: como surge e o que representa para a suinocultura. Acta Scie Vet, v.37, p.147-150, 2009.

Viana FAB. Guia terapêutico veterinário. $3^{\circ}$ ed. Lagoa Santa - MG. Gráfica e Editora CEM, 2014. 